\title{
Exploring factory digital production support system through the lens of Service Dominant logic
}

\author{
Shaun West $^{1,{ }^{*}}$, Yann Keiser ${ }^{2}$, Oliver Stoll ${ }^{1}$ and Simon Züst ${ }^{1}$ \\ ${ }^{1}$ Luzern University of Applied Science and Art, Technikumstrasse 21, 6048 Horw, Switzerland \\ ${ }^{2}$ Luzern University of Applied Science and Art, Suurstoffi 1, 6343 Rotkreuz,Switzerland
}

\begin{abstract}
This paper attempts to understand innovation in the production environment of three different digital systems that support the manufacturing processes of industrial firms. Three cases were characterized through the lens of Service Dominant logic to assess the "smartness" of the services that the system provides. It achieves this using the dimensions 'service ecosystem', 'service platform' and 'value cocreation'. The assumption used is that production or assembly may be viewed as a set of processes and hence in effect, a service. Furthermore, the digital system provided institutional arrangements to support value cocreation. It was found that the digital systems provide services to the shop floor and management over different time frames. What was also identified from the analysis was that by using the three dimensions, it was possible to understand the system's limitations in terms of supporting the value cocreation processes.
\end{abstract}

\section{Introduction}

Research today confirms an interest in the digital transformation of industrial firms $[1,2]$, and many studies have considered the role of emerging technologies - often called the fourth industrial revolution (Industry 4.0) - as key to improving the competitiveness of a manufacturing firm [3]. Competitiveness improvements come in many forms [1,3]: new business models, new value propositions, or greater productivity. Within firms, the use of digital technologies to support the business (i.e., ERP), to support sales (i.e., CRM), or to support production (i.e., MES) have become commonplace. It is possible to consider all operational transactions and processes within the firm and, therefore, service operations between individual actors (both people and machines) [4]. This is, in fact, very close to the approach taken in Lean manufacturing, where the process diagram is used to help understand process steps at both micro and meso levels [5].

Manufacturing as a service is not a new concept, however with new digital technologies, it is now possible to have service-orientated smart manufacturing based on Ind4.0 approaches [6]. With the transition to "lot size one", manufacturing becomes more

${ }^{*}$ Corresponding author: $\underline{\text { shaun.west } @ \text { hslu.ch }}$ 
complex and demanding for basic scheduling, production planning and maintenance [7]. The operation of production facilities with high levels of customer-specific requirements runs the risk of poor quality where digital technologies do not support the production process.

Minimal consideration has been given to how these new digital technologies can support value co-creation as defined within the theoretical premise of service science and, more particularly, Service Dominant (SD) logic [8,9]. Many of the service innovation characteristics of these industrial platform-based technologies has been overlooked, even though they describe service innovation [8] within the perspective of SD logic [9]. The use of new digital platform-based technologies in a production environment allows the creation of unique ecosystems of multiple actors that are continually interactive. The operant and operand resources can be integrated and exchanged in these systems, supporting the beneficiary's value co-creation process [10]. The operant resources can be viewed as basic, composite, or interconnected within a firm and enable the firm to produce efficiently [11]. Therefore, any digital system that can support the integration of the operant resources is in line with SD logic. The integration of operant and operand resources requires institutional arrangements, which may be supported through digital technologies as they behave as resource integrators [10].

This paper assesses the "Smartness" of three digital systems in "lot size one" production environments based on the ability of the digital strategy to support the value co-creation processes within the production and assembly environment of a firm. An alternative approach would have been to apply Lean methods to assess the contribution of the system to the firm's success by employing more traditional production metrics [12], although there are challenges in lot-size one production environments of applying such approaches [13]. Therefore, by focusing on value co-creation and SD logic, we consider that the assessment of the digital systems would be enhanced. Based on this, the research question for this study is: "does the framework for the assessment of smart services support the development of digital production support system?". It is anticipated that we will also learn how to design a digital system that captures the basics, then scales, and is future proof, particularly when the firm does not know its initial needs, never mind future requirements. Using this approach, the focus will be on each system, how they are designed for the individual applications and will not focus on the firm supplying the system.

This paper is structured as follows, background where the underlying concepts are described, the methodology to provide insights to how the research question was answered, the results and analysis, a discussion structured around the framework and also providing managerial and theoretical insights, and, finally the conclusions with recommendations.

\section{Background}

The following paragraph provides background information on the changes in customer demand and the digital transformation in production systems. This leads to a data-driven view of a production system which is connected to the concept of value co-creation.

\subsection{Customer demands and new technologies drive change in production systems}

To fulfil the requirements of more and more customer-individual products within production systems [2, 14], integrated business solutions are needed [15]. Through digital technologies, the flexibility and service orientation that are needed can be achieved [16]. Understanding the production system as well as production planning are key aspects to success in future strategic positioning $[1,2$,$] . These dimensions are build basics to realize$ 
the increasing complexity and variety in market demand within the production. The flexibility of production systems and the changes in the market require a correspondingly adapted understanding of production planning.

Industry 4.0 is better known as the 'Smart Factory', referring to the fourth industrial revolution where manufacturing collaborates with new (information) technologies to increase output $[1,14]$. These technologies enable the "development of the value chain resulting in reduced manufacturing lead times, improved product quality, and organizational performance" $[4,16]$. Advances in communication technology have a major impact on this transformation to interconnected manufacturing elements and to so-called cyber physical systems [2]. Therefore, physical devices are enriched with sensors, processors, communication technologies, etc. to ensure information exchange between humans, and between machines, but also between humans and machines [17]. An integration across the value stream leads to an IT-enabled production process with customized products. However, human capabilities should be enhanced by smart solutions on the shop floor and not be replaced by them [4]. Through the application of Industry 4.0 technologies, a high level of process integration in human-machine collaboration can be achieved, particularly shop floor equipment integration [16, 17].

A good starting point for improvement of the production system would be the holistic application of Lean principles [14]. Nonetheless, many manufacturing systems are still based on the traditional batch and queue principles instead of single piece flow, which has a considerably shorter process lead time $[18,19,20]$. Lean is often oversimplified and reduced to the concept of Kaizen (i.e., continuous improvement) and elimination of Muda (i.e., waste elimination) [14]. Further, the authors explain that it needs to be understood that Lean is not a toolbox, but more of a synergic tool system. At this point, the normal twopillar Toyota Production System usually leads to isolated tools being selected, which will lead to an improvement but probably not to a stable optimum [14].

Using Lean as a foundation, smart manufacturing (i.e., focusing on data and data analytics) is enabled through the use of new data resources [4]. Aiming for more agile operation and learning factory, in a continuously changing environment means that organizational and cultural aspects more relevant than the technical aspects [18, 21].

\subsection{Data-driven sustainable production system}

To reveal the full potential of Industry 4.0, a rise of integrated key technologies vertically and horizontally is needed $[4,16]$. While integration should help to support industrial business processes and business networks, the focus relies on a consistent solution [22]. According to Abele et al. [22], the horizontal integration links processes within the value stream, while the vertical layer focuses on hierarchical integration. End-to-end integration will be enabled by these horizontally and vertically integrated layers, whereas horizontal integration also allows the integration of multiple factories through a value network. In order to achieve the objective of smart factories, data collection and data processing within the value stream is crucial $[19,21]$.

One tool which helps with decision-making to optimize production output is the manufacturing execution system (MES) $[19,23,24]$. Current performance indicators of production are visualized on a dashboard. MES are generally task oriented and lack forward looking analytics and prediction technologies [23], however, connecting manufacturing elements and making use of data is a key element of Industry 4.0 and provides opportunities to enhance production efficiency [22]. Making use of data should not be restricted to MESs, it should also be connected to product life cycles [17]. As illustrated in their work, collecting and aggregating data of different sources leads to some sort of a data lake, from which insights can then be drawn through advanced analytics. Analytics can be 
performed on different autonomy levels, providing deeper insights [25]. This helps to determine the degree of autonomy for a specific use case. An example of advanced analytics is a production twin that focuses mainly on planning, increasing production efficiency, and reducing throughput times through simulation or improved operations cost $[26,27]$.

In summary, the convergence of the real and digital worlds is creating new potential to increase productivity. Simulations and data analytics are the basis for understanding and optimizing current processes in a more adaptable and agile way.

\subsection{Concepts that underpin value co-creation}

SD logic is a meta-theoretical framework that challenges traditional goods dominant logic that is has been used in many industrial environments [28]. Initially, it emerged from the academic marketing area as its core was the view of value co-creation [29, 30,31]. SD logic provides a view of value co-creation based on ten premises and five axioms; critically, they state that value is always co-created by multiple actors and that the value co-creation process needs institutional arrangements to coordinate the process. The development of solutions, therefore, needs multiple actors from within the relevant ecosystem.

Digital technologies can provide the necessary institutional arrangements to support the value co-creation process as they can act as resource-integrators [32]. Moreover, digital technologies allow digital resources to become accessible across a system and accessible to more actors, including potential beneficiaries, therefore opening up new value co-creation opportunities $[9,24,34]$.

Three dimensions relevant to service innovation in the digital age [35]: service ecosystem, service platform, and value co-creation. Underlying these, there are ten characteristics from the SD logic literature that were important for value co-creation. Their paper linked the term "smart" with the potential for value co-creation offered by a digital solution, which is in line with some of the literature [36, 37]. The use of "potential" supporting value co-creation is important, as the value can only be determined by the beneficiary and within a specific context [38]. More technical definitions of "smart" that do not consider value co-creation are excluded [39].

\section{Methodology}

Research based on multiple case studies with further analysis was selected for this study [40] in order to answer the research question. Three cases were developed based on the research of two of the authors. The cases were selected because they are all based in the production environments of firms, and in all cases the authors have several years of experience with the firms. Also important was that the three cases are from manufacturing firms with high degrees of product variance.

Development of each case followed a similar approach, initially creating a contextual description, identifying the actors, the approach applied to identify the system's requirements, and the actors' expectations in the short- and long-term. A sketch of the problem space, describing the actors, material flows, information flows and machines was created to support building a common understanding of the problem space. This approach was taken in each of the cases to understand the requirements of the digital system.

The actors' expectations were then used to provide detailed solutions for the firms, which are reported in this study, to help answer the research question, having been assessed through the lens of S D logic [35]. The scoring was undertaken independently by each of the authors prior to a joint assessment by all authors using a 5-point Likert scale was applied [41]. The criteria were rated from 1 (poor) to 5 (excellent). The cross-case analysis 
also included an assessment of the level of the Industry 4.0 complexity level of the solutions [25].

Table 1. Basic data capture for the cases

\begin{tabular}{ll}
\hline $\begin{array}{l}\text { Contextual } \\
\text { description }\end{array}$ & $\begin{array}{l}\text { Problem description; target market; conceptual solution; expected } \\
\text { impacts; comments }\end{array}$ \\
\hline Actors & Identification of actors and roles \\
\hline $\begin{array}{l}\text { Approach to } \\
\text { identify } \\
\text { requirements }\end{array}$ & $\begin{array}{l}\text { Insight into the process used to capture the digital system's } \\
\text { requirements and the actors' expectations in the short- and long- }\end{array}$ \\
\hline
\end{tabular}

\section{Results and analysis}

The results introduce each case from different perspectives. All of the cases follow the same general structure to help describe the context in terms of the business case, the assumed business case, the actors, the approach taken to identify the requirements in both a short and longer-term. An example of the problem space is provided for each case to help the readers understand the complexity of each case. The section closes with a comparison of the cases based on the "smartness" Framework [35].

\subsection{Case 1 - improving assembly activities for configured-to-order production}

Case 1 (details in Table 2 and Fig. 1) is based on an industrial equipment firm that manufactures and assembles configured-to-order products used in many process industries. The firm is well established in these segments and has made considerable investments in Lean and process improvements.

The main area of focus here is around the visibility of assembly activities at the local level. Operators rely on multiple data systems, with duplicated information introducing errors and delays. Also, they have a high dependency on paper reports and change notifications, requiring manual version control from supervisors. Their initial objective was a system that integrates resource planning system and document management into the core enterprise and replaces excel and paper side systems. The system should eventually incorporate life-management systems and lay the foundations for machine monitoring and control in the medium term. As a long-term aim, the solution should scale to cover other sites and allow for cross-site analytics.

Critical stakeholders for this effort are local production management, operations, logistics, and product development, supported by IT Infrastructure, Service, Information Security, and Integration teams.

Initial areas of focus were gathered via an interview with the key stakeholders and validated via observation of real-life occurrences. Requirements were captured as highlevel functions and weighted according to importance. As part of a vendor review, the team performed a gap analysis on the available function and mapped it to the defined to-be process.

During the first phase, they focused on integration into the existing resource planning system and improving the process for individual product ranges. For a later second phase, they would integrate the digital production support system with the shop-floor machines. 
Table 2 Contextual description for case 1

\begin{tabular}{ll}
\hline $\begin{array}{l}\text { Problem } \\
\text { description }\end{array}$ & $\begin{array}{l}\text { Current systems lack visibility at production level } \\
\text { Operators rely on multiple information sources } \\
\text { Unnecessary worker motion }\end{array}$ \\
\hline Target markets & Configured-to-order asset operators in process industry \\
\hline $\begin{array}{l}\text { Conceptual } \\
\text { solution }\end{array}$ & 'Traditional' on-premises MES solution \\
\hline Impact & $\begin{array}{l}\text { Improved production visibility via more granular and timely } \\
\text { reporting, available at operator workstations }\end{array}$ \\
& $\begin{array}{l}\text { Increased support effort on local IT function } \\
\text { Minimal impact on ERP function and maintenance }\end{array}$ \\
\hline Comments & $\begin{array}{l}\text { Significant experience in process improvement } \\
\text { 'Bottom up' improvement culture } \\
\end{array}$ \\
& Focus on the process rather than the software \\
\hline
\end{tabular}

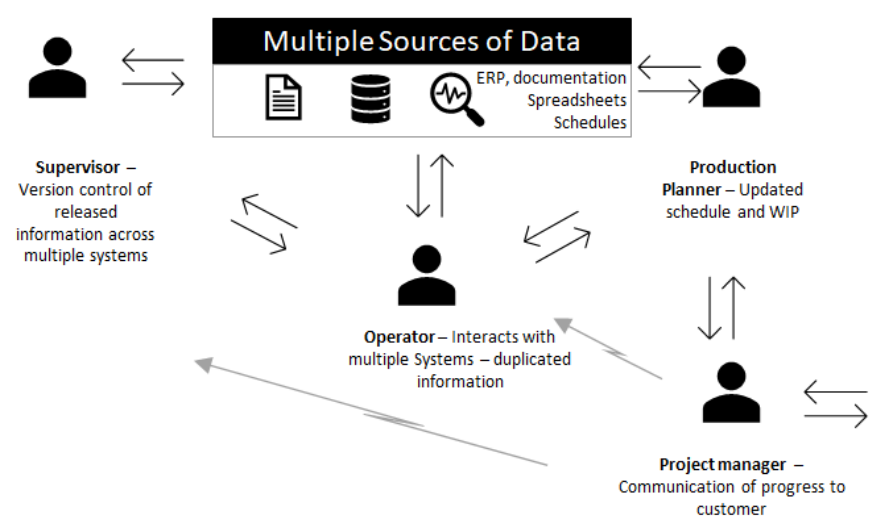

Fig. 1. Multiple resources of data and multiple actors within the system

\subsection{Case 2 - supporting purchase decisions to ensure material availability}

Case 2 (details in Table 3 and Fig. 2) considers a design-to-order SME. The company designs and manufactures furniture based on individual customer requirements. The firm aimed to increase the efficiency and flexibility of the production processes. To achieve this, they identified that they would need a new digital system to connect all of the processes and provide higher-level analytics.

The firm identified five use cases via a hybrid Design Thinking/Lean approach. This was achieved through the active involvement of external experts and employees, directly and indirectly involved in the production process. The process within the factory was based on design-to-order, with many different configurations for the final goods. Materials flows within the business were critical, and having the materials available enabled the firm to manufacture the final goods via a complex process of cutting, coating, and assembly. There were many manufacturing pathways within the system, although all ended with the goods being loaded directly onto the delivery lorry. The manufacturing process impacted many different departments within the firm and many different workstations. 
Table 3. Contextual description for case 2

\begin{tabular}{ll}
\hline $\begin{array}{l}\text { Problem } \\
\text { description }\end{array}$ & $\begin{array}{l}\text { Lead time of material orders is longer than the lead time for product } \\
\text { orders. } \\
\text { Procurement orders material without reliable sales forecasts. }\end{array}$ \\
\hline $\begin{array}{l}\text { Target } \\
\text { markets }\end{array}$ & Designed-to-order furniture for homes (B2B and B2C markets) \\
\hline $\begin{array}{l}\text { Conceptual } \\
\text { solution }\end{array}$ & $\begin{array}{l}\text { Building, evaluation, and implementation of a methodology to } \\
\text { support purchase decisions by use of data. }\end{array}$ \\
\hline Impact & $\begin{array}{l}\text { Improvement of the order fulfillment while decreasing fixed costs } \\
\text { and average inventory on hand. }\end{array}$ \\
\hline Comments & $\begin{array}{l}\text { Proof of concept showed that the built model provides a feasible } \\
\text { solution. Evaluation of more articles is needed. } \\
\text { Expect further system integration. }\end{array}$ \\
\hline
\end{tabular}

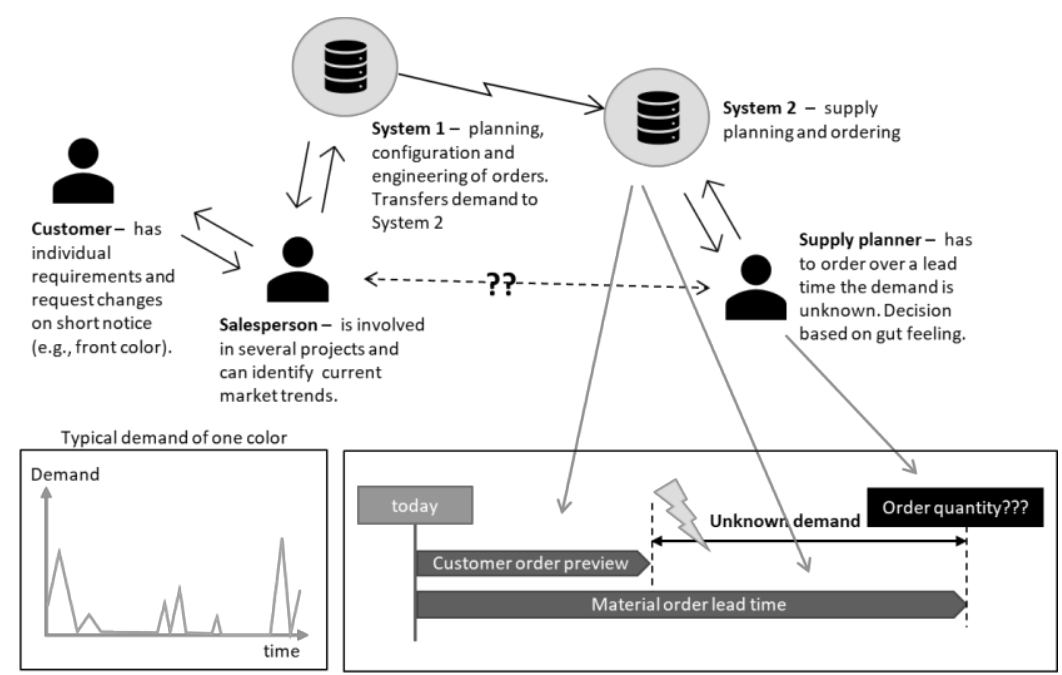

Fig. 2. Multiple resources of data and actors with problem space visualization

Material lead times were causing problems in production operation, as lead times were extending, and the customer lead times had not been extended to accommodate the change in lead times. Historical data was used to help forecast demand, yet this was based on stand-alone systems with limited access to monitoring. The firm did not have an appropriate system to support decision-making in production between different actors (i.e., procurement, production, and sales). Other constraints within the firm's resources existed. Many of the staff were concerned with the warehouse capacity, which could not be adapted in the short-term, and in the longer term could be extended only at a high cost.

The proof of concept was developed and tested locally. This testing could be moved to a cloud for more advanced analytics. The proof of concept supported the different actors and allowed them to jointly make decisions to improve production and better match demand with supply.

\subsection{Case 3-configured to order for process engineering products}

Case 3 (details in Table 4 and Fig. 3) is from an engineering company that manufactures configured-to-order modular components used in production industries, such as downstream oil and gas, and pharmaceuticals. The firm is a well-established company but less experienced with process improvement methodologies. The company has an existing 
investment in PLC systems, and telemetry data is available, although with some significant gaps, and this needs manual collection and analysis in spreadsheets.

Table 4. Contextual description for case 3

\begin{tabular}{|c|c|}
\hline $\begin{array}{l}\text { Problem } \\
\text { description }\end{array}$ & $\begin{array}{l}\text { Mismatch between booked hours and material usage. } \\
\text { Infrequent and manual reporting obscures issues } \\
\text { Data generated but not complete and not applied to root cause } \\
\text { analysis } \\
\text { Best practices not shared between sites }\end{array}$ \\
\hline $\begin{array}{l}\text { Target } \\
\text { markets }\end{array}$ & Configured-to-order process engineering modules \\
\hline $\begin{array}{l}\text { Conceptual } \\
\text { solution }\end{array}$ & $\begin{array}{l}\text { Bespoke IoT monitoring solution } \\
\text { Cross site implementation }\end{array}$ \\
\hline Impact & $\begin{array}{l}\text { Greater visibility of production progress } \\
\text { Cross site comparison and potential for load balancing } \\
\text { Some process alignment between sites }\end{array}$ \\
\hline Comments & $\begin{array}{l}\text { Less experience in process improvement } \\
\text { 'Top down' improvements, required local acceptance } \\
\text { Up-front effort. Many changes at once, simplified ongoing } \\
\text { management }\end{array}$ \\
\hline
\end{tabular}

The firm has identified issues with the visibility of operations at a global level and operator level. Most notably, with the production line monitoring of machine telemetry data, used to gauge progress at machine, line, site, and enterprise levels. It has been highlighted by the global operations team that there are often discrepancies between booked hours and material usage. These issues prove challenging to investigate remotely because reporting is manual and infrequent.

In the long term, the aim is to connect all sites and share best practices. Key stakeholders are global operations, local operations, senior site management, senior global management, and local IT. Given the high-level needs, a cross-site team was assembled to ensure a solution was fit-for-purpose across all of the firm's installations, along with the strategic software vendor. This caused considerable overheads in the preparatory stages of the project, with the team needing to compare and align standard processes across a range of ERP systems. Key terminology and KPIs were defined in a shared glossary, and key processes were mapped.

Needs were captured as high-level user stories (covering requirements and acceptance criteria) and reviewed by the team and vendor, with multiple sessions to clarify. Overall equipment effectiveness measurement at the production level and inter and cross-site comparisons were highlighted as the highest priorities. Long-term needs were out of this study's immediate scope, however, the need to use the data at a later stage for deeper analytics is considered necessary.

As the focus was on monitoring and used shop floor systems rather than adding an additional system, it was agreed that a cloud-based monitoring system, with some edge devices, was used to collate disparate data into common structures. This resulted in reducing the local IT components (such as database and web servers) but still required significant local investment to capture and unify data from existing machine-based systems and re-architect these areas into an operational environment that could push data to a cloud application. 


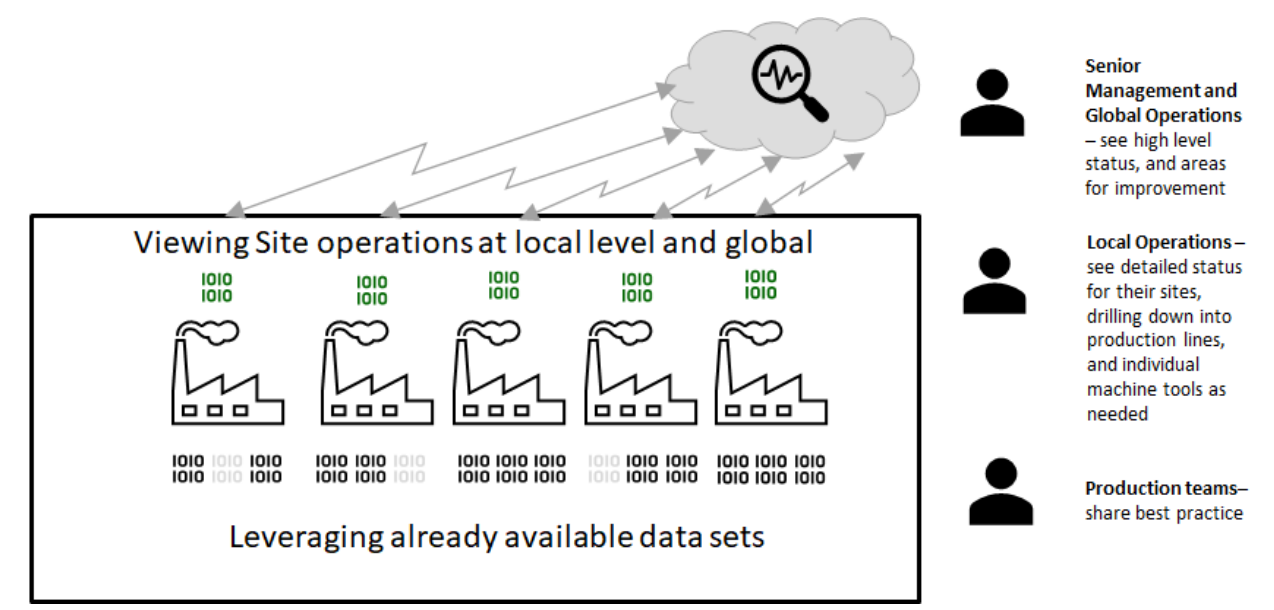

Fig. 3. Multiple actors and multiple sites

\section{Discussion}

The discussion of the results opens by first comparing the 'smartness' of the three cases and the level of the monitoring and diagnostics. Before moving to the discussion of the individual major dimensions, the discussion considers the impact on monitoring and diagnostics aspects. The managerial and theoretical implications close the discussion.

\subsection{Case analysis based on the "smartness" framework}

First, the three cases are considered to confirm their suitability for a cross-case analysis (Table 5). This includes an assessment of the use cases and the approaches taken to help identify the requirements, before moving to the assessment of the value co-creation when viewed through the lens of SD logic. The level of the monitoring and diagnostics for the short- and long-term is provided in the table for ease of comparison.

Table 5. Cross-case analysis of the three cases

\begin{tabular}{llccc}
\hline Major Dimensions & Key Characteristics & Case 1 & Case 2 & Case 3 \\
\hline Service Ecosystem & Flexibility \& integrity & 4 & 4 & 2 \\
& Shared view & 4 & 4 & 2 \\
& Actor roles & 3 & 3 & 3 \\
& Architecture & 3 & 2 & 3 \\
\hline Service Platform & Modular structure & 4 & 4 & 2 \\
& Rules of exchange & 3 & 3 & 2 \\
\hline Value co-creation & Value creation between actors & 4 & 3 & 4 \\
& Interactions between diverse actors & 3 & 2 & 4 \\
& Accommodation of roles & 2 & 2 & 3 \\
& Resource integration & 3 & 2 & 3 \\
\hline Monitoring and & Short-term & 1 & 2 & 3 \\
diagnostics level & Longer-term & 4 & 4 & 3 \\
\hline
\end{tabular}

The discussion will open with the three SD logic major dimensions that align with the value co-creation potential that the digital systems could provide [35]. After considering these, the discussion focuses on the more technical aspects of the levels of monitoring and diagnostics, which have been described in the short term and the long term. This aspect considers the future-proofing of the systems and is therefore associated with the 
sustainability of the potential value co-creation offered. The section closes with managerial and theoretical implications.

\subsection{Manufacturing smartness considerations}

This section considers SD-logic in manufacturing and does this by considering the service ecosystem, the service platform and the value co-creation [35], it closes by discussing the monitoring and diagnosis aspects.

\subsubsection{Service Ecosystem}

All of the digital systems are connected to complex systems (ecosystems) where the actors are a mix of individuals or teams with different roles within the ecosystem. The resources within the system were materials, including the consumables needed for the tasks, and the machines and equipment. The digital technologies support and aid the flows of information to the individual actors. The use of the assessment framework [35] helped the development teams to understand the limitations that they were designing into the system. Limitations that may not have otherwise been considered based on the traditional 'need finding'.

Case 1 scored highly as it provided support for many interactions and touchpoints by integrating core systems and replacing side systems. It also automated the management of the data ensuring the correct information is available for all actors when needed, in a form in which they could consume. Case 2 provides flexibility in integration, since it is a basic concept and can be integrated either in the existing information system environment or via a separate app. Different actors need the process to run smoothly so they can focus on their own jobs. The final case (Case 3) was developed to allow the firm to consider the strategic portfolio view of the operations and therefore rates highly on the architecture and its ability to provide multi-role perspectives. This was important as the system provided in effect a system-of-systems perspective, with the purpose of high-level comparisons and opportunities for best practice sharing and targeted workload balancing

\subsubsection{Service Platform}

The consideration of the service platform, which is in effect at the core of the digital technologies, provided a surprisingly wide range of rankings. Cases 1 and 2 scored highly, whereas Case 3 was significantly poorer.

The modular structure was at the core of the technology in Case 1, as in part, it came from the need to grow as new needs arise and allow standardization opportunities across the firm's divisions. For Case 2, there was a managerial preference for a modular/ scalable solution, as the concept is expected to adapt to a wider range of production and supply chain problems in the future. Case 3 was designed to unify multiple disparate systems into a global, centralized platform, and so the modular structure was considered less important.

Considering the rules of exchange between alternative systems and platforms, Cases 1 and 2 scored best as they both had the need to scale and connect with other systems. Case 3 was different and was not fully considered, although in hindsight, the assumption may prove to be incorrect.

\subsubsection{Value co-creation}

This is, in effect, the aspect of core importance for this paper and is based on the current systems installed rather than the future potential. Value co-creation occurs when two or more actors collaborate, and here the digital technology supports the resource integration 
and allows different actors to collaborate on multiple time horizons and with different roles. In effect, supporting decision making on the micro-level.

All of the cases support value creation between multiple actors and, as a consequence, reflect the social interactions that take place in an operational environment. The cases show a different approach to diverse actors, Case 3 performs poorly compared with the other two cases, suggesting that in the longer-term the initial premise may be questioned. Case 1 provided examples of integration with actors external to the firm as well as internal actors. Case 2 wanted to integrate more internally within the firm to include sales, who would then (outside the system) contact their customers. The accommodation of roles in Cases 1 and 2 was considered more as an afterthought, and it is assumed in the longer-term this will be adapted. Interestingly, Case 2 suffered with both the integration of roles and resource integration and may suggest a lower level of maturity of applications or from a focus to have a system up and running. Case 3 demonstrated better accommodation of roles however, this may be due to a more focused application. Resource integration was for both Cases 1 and 3 high, reflecting the individual cases, one being focused on a single complex production system, whereas Case 3 was a system of factories. Case 2 has a "simple" mission to integrate resources within a single production facility.

\subsubsection{Monitoring and diagnostics level}

The short-term versus the longer-term expectations of the level of M\&D capabilities [25] confirmed that Cases 1 and 2 are both expected to improve and move towards a more advanced analytical approach based on the lessons learnt from the use of the digital technologies. This is a clear phased approach, based on modules, and would be expected to support change management. Case 3 , on the other hand, had a very simple road map with limited additional integration of new technologies into the system. This may be premature as, with use, any digital system generates new understandings of how it could support value co-creation through further resource integration, however, the business case was based on basic monitoring.

\subsection{Managerial implications}

The cases all have many actors, many machines, and many processes and viewpoints involved. A key aspect of factory digitization is arguably less the technology implementation per se but the opportunity to review and optimize foundational processes (potentially for the first time in many years) and ensure that they are still fit-for-purpose $[4,17,25]$. The digitalization aspect allows an ongoing measurement to ensure adherence to process and continued improvement. A common first step for all these efforts was to establish a shared problem space, and on reflection it can be seen that this is contextdependent. There are several levels to this with very different needs served, but all are required to ensure value co-creation. The operational/production line level considerations are on ensuring performance, machine availability, and minimizing defects. A more holistic approach for resource planning and work status is the focus at the site level. In contrast, at the enterprise level, the focus becomes more strategic, with questions such as 'what are the best-performing sites, products, or lines, and how can we optimize our workloads?'. This builds upon the connection and integration of resources within the factory environment $[4,11,14,17,18]$. As a final management reflection, is it easier to focus on the technology aspects rather than the development of a smart digital technology to support production? 


\subsection{Theoretical implications}

On a practical basis, the framework [35] supported the decision-making processes for developing the systems, ensuring that opportunities were not overlooked during the design phase thus, bridging the gap between the meta-theoretical approach of SD logic and supporting its operationalization. Furthermore, the framework provides a prompt to the development team (supporting value co-creation) to consider non-technical aspects that could support value co-creation during the system's use. Doing so helps the team to move past the technological elements and consider the application more widely, and builds upon the literature $[29,32,33,34]$.

Focusing on SD logic theory [38], the cases demonstrated that transforming raw materials into finished goods is a complex set of operations in a complex ecosystem with system orchestration where service is the fundamental basis of exchange (FP2). Making operant resources more freely available to the actors provides the strategic rationale for digitalization (FP4). Production itself involves many actors (including beneficiaries) and resources and different levels (micro and meso) that interact and co-create value both throughout the initial set-up of a digital system to support production, and during the operational use of such a system (axiom 2). The value co-creation is supported by the institutional arrangements provided by the digital technologies, which were, in fact, actorgenerated (axiom 5).

\section{Conclusions and recommendations}

This study considers three different applications of factory-based digital technologies to support production planning and control. Each of the systems reviewed had the common theme of many actors, many machines, and many processes, and all were based on made to order manufacturing environments. The development of the systems was led by IT-trained people, and they wanted to create a system that would be able to support value co-creation through the application of the digital technology they were using, rather than the more deterministic approaches of more traditional MES. Although in different firms, each application was developed through the integration of input from different actors from the wider production environment.

The use of the "smartness" framework [35] provided an additional set of questions for the development teams, which otherwise might have been overlooked. The use of the framework was reductionist compared with the full set of SD logic axioms and foundational premises, nevertheless during the development phase it provided a practical approach that helped to realize a non-technical view of "smart" through a potentially more abstract consideration of "value co-creation".

The three cases confirmed that production processes can be considered in terms of a set of service operations. The digital systems provide the institutional arrangements that support the value co-creation processes amongst diverse actors through the integration of resources in new ways. Within service sciences, the application of SD logic is well described However, within the information science community it is less well known and applied, and therefore it is recommended that more practical approaches to its application are developed.

This work is a snapshot of three cases, over a short timeframe, and this will create limitations to the applicability of the results. It is recommended that the systems are reassessed in 18-24 months' time to re-confirm the systems' 'smartness' and the ability of the systems to support value co-creation. Therefore, the validity of this multiple case study can be further elaborated. 


\section{Acknowledgements}

The authors would like to thank HSLU and the industrial partners for their support with this study into Industry 4.0.

\section{References}

1. Kamble, Sachin S., Angappa Gunasekaran, and Shradha A. Gawankar. "Sustainable Industry 4.0 Framework: A Systematic Literature Review Identifying the Current Trends and Future Perspectives." Process Safety and Environmental Protection 117 (2018). https://doi.org/10.1016/j.psep.2018.05.009.

2. Bauernhansl, Thomas. "Die Vierte Industrielle Revolution - Der Weg in Ein Wertschaffendes Produktionsparadigma.” In Handbuch Industrie 4.0 Bd.4, 2017. https://doi.org/10.1007/978-3-662-53254-6_1.

3. Lars Fend, and Jürgen Hofmann. Digitalisierung in Industrie-, Handels- Und Dienstleistungsunternehmen. Digitalisierung in Industrie-, Handels- Und Dienstleistungsunternehmen, 2020. https://doi.org/10.1007/978-3-658-26964-7.

4. Mittal, Sameer, Muztoba Ahmad Khan, David Romero, and Thorsten Wuest. "Smart Manufacturing: Characteristics, Technologies and Enabling Factors." Proceedings of the Institution of Mechanical Engineers, Part B: Journal of Engineering Manufacture 233, no. 5 (2019). https://doi.org/10.1177/0954405417736547.

5. Mercado, Vanessa Valle, Dayana Benitez Acosta, Dionicio Neira Rodado, Juan Cabarcas Reyes, Aurora Piñeres Castillo, and Guilherme Luz Tortorella. "Design of Lean Manufacturing-Based Strategies to Improve the Production Process of a Metalworking Company." International Journal of Services and Operations Management 38, no. 4 (2021). https://doi.org/10.1504/IJSOM.2021.114251.

6. Tao, Fei, and Qinglin Qi. "New IT Driven Service-Oriented Smart Manufacturing: Framework and Characteristics." IEEE Transactions on Systems, Man, and Cybernetics: Systems 49, no. 1 (2019). https://doi.org/10.1109/TSMC.2017.2723764.

7. Lachenmaier, Jens F., Heiner Lasi, and Hans Georg Kemper. "Simulation of Production Processes Involving Cyber-Physical Systems." In Procedia CIRP, Vol. 62, 2017. https://doi.org/10.1016/j.procir.2016.06.074.

8. Barrett, Michael, Elizabeth Davidson, Jaideep Prabhu, and Stephen L. Vargo. "Service Innovation in the Digital Age: Key Contributions and Future Directions." MIS Quarterly: Management Information Systems 39, no. 1 (2015). https://doi.org/10.25300/MISQ/2015/39:1.03.

9. Lusch, Robert F, and Satish Nambisan. "Service Innovation in the Digital Age: A Service-Dominant Logic Perspective.” MIS Quarterly 39, no. 1 (2015).

10. Nambisan, Satish. "Information Technology and Product/Service Innovation: A Brief Assessment and Some Suggestions for Future Research." Journal of the Association for Information Systems 14, no. 4 (2013). https://doi.org/10.17705/1jais.00327.

11. Madhavaram, Sreedhar, and Shelby D. Hunt. "The Service-Dominant Logic and a Hierarchy of Operant Resources: Developing Masterful Operant Resources and Implications for Marketing Strategy." Journal of the Academy of Marketing Science 36, no. 1 (2008). https://doi.org/10.1007/s11747-007-0063-z.

12. Charaf, Karim, and Huifang Ding. "Is Overall Equipment Effectiveness (OEE) Universally Applicable? The Case of Saint-Gobain.” International Journal of Economics and Finance 7, no. 2 (2015). https://doi.org/10.5539/ijef.v7n2p241. 
13. Andersson, C., and M. Bellgran. "On the Complexity of Using Performance Measures: Enhancing Sustained Production Improvement Capability by Combining OEE and Productivity." Journal of Manufacturing Systems 35 (2015). https://doi.org/10.1016/j.jmsy.2014.12.003.

14. Rüttimann, Bruno G., and Martin T. Stöckli. "Going beyond Triviality: The Toyota Production System — Lean Manufacturing beyond Muda and Kaizen.” Journal of Service Science and Management 09, no. 02 (2016). https://doi.org/10.4236/jssm.2016.92018.

15. Dombrowski, Uwe, Philipp Krenkel, and Miriam Hermann. "Ganzheitliches Informationsmanagement Im Kontext von Industrie 4.0.” ZWF Zeitschrift Für Wirtschaftlichen Fabrikbetrieb 113, no. 12 (2018). https://doi.org/10.3139/104.112022.

16. Mittal, Sameer, Muztoba Ahmad Khan, David Romero, and Thorsten Wuest. "A Critical Review of Smart Manufacturing \& Industry 4.0 Maturity Models: Implications for Small and Medium-Sized Enterprises (SMEs)." Journal of Manufacturing Systems 49, no. October (2018): 194-214. https://doi.org/10.1016/j.jmsy.2018.10.005.

17. Romero, David, Johan Stahre, Thorsten Wuest, Ovidiu Noran, Peter Bernus, Åsa FastBerglund, and Dominic Gorecky. "Towards an Operator 4.0 Typology: A HumanCentric Perspective on the Fourth Industrial Revolution Technologies." In CIE 2016: 46th International Conferences on Computers and Industrial Engineering, 2016.

18. Chowdhury, Tahsin Mahmud, and Homero Murzi. "The Evolution of Teamwork in Engineering Workplace from First Industry Revolution to Industry 4.0: A Literature Review." In ASEE Annual Conference and Exposition, Conference Proceedings, Vol. 2020-June, 2020. https://doi.org/10.18260/1-2--35318.

19. Perico, Paolo, Emrah Arica, Daryl J. Powell, and Paolo Gaiardelli. "MES as an Enabler of Lean Manufacturing.” In IFAC-PapersOnLine, Vol. 52, 2019. https://doi.org/10.1016/j.ifacol.2019.11.306.

20. Invernizzi, Daniela, Paolo Gaiardelli, Emrah Arica, and Daryl Powell. "MES Implementation: Critical Success Factors and Organizational Readiness Model.” In IFIP Advances in Information and Communication Technology, Vol. 567, 2019. https://doi.org/10.1007/978-3-030-29996-5_57.

21. Westkämper, Engelbert. “Zukunftsperspektiven Der Digitalen Produktion.” In Digitale Produktion, 2013. https://doi.org/10.1007/978-3-642-20259-9_24.

22. Abele, Eberhard, Reiner Anderl, Joachim Metternich, Andreas Wank, Oleg Anokhin, Alexander Arndt, Tobias Meudt, and Markus Sauer. "Effiziente Fabrik 4.0: Einzug von Industrie 4.0 in Bestehende Produktionssysteme." ZWF Zeitschrift Fuer Wirtschaftlichen Fabrikbetrieb 110, no. 3 (2015). https://doi.org/10.3139/104.111293.

23. Almada-Lobo, Francisco. "The Industry 4.0 Revolution and the Future of Manufacturing Execution Systems (MES).” Journal of Innovation Management 3, no. 4 (2016). https://doi.org/10.24840/2183-0606_003.004_0003.

24. Schleipen, Miriam, Ansgar Münnemann, and Olaf Sauer. "Interoperabilität von Manufacturing Execution Systems (MES).” At - Automatisierungstechnik 59, no. 7 (2011). https://doi.org/10.1524/auto.2011.0936.

25. Porter, Michael E., and James E. Heppelmann. "How Smart, Connected Products Are Transforming Companies.” Harvard Business Review, 2015.

26. Jones, David, Chris Snider, Aydin Nassehi, Jason Yon, and Ben Hicks. "Characterising the Digital Twin: A Systematic Literature Review." CIRP Journal of Manufacturing Science and Technology 29 (2020). https://doi.org/10.1016/j.cirpj.2020.02.002. 
27. Kritzinger, Werner, Matthias Karner, Georg Traar, Jan Henjes, and Wilfried Sihn. "Digital Twin in Manufacturing: A Categorical Literature Review and Classification," Vol. 51, 2018. https://doi.org/10.1016/j.ifacol.2018.08.474.

28. Vargo, Stephen L., and Robert F. Lusch. "Evolving to a New Dominant Logic for Marketing." Journal of Marketing 68, no. 1 (2004). https://doi.org/10.1509/jmkg.68.1.1.24036.

29. Maglio, Paul P., Stephen L. Vargo, Nathan Caswell, and Jim Spohrer. "The Service System Is the Basic Abstraction of Service Science." Information Systems and EBusiness Management 7, no. 4 SPEC. ISS. (2009). https://doi.org/10.1007/s10257-0080105-1.

30. Lusch, Robert F., and Stephen L. Vargo. "Service-Dominant Logic: Reactions, Reflections and Refinements." Marketing Theory 6, no. 3 (2006). https://doi.org/10.1177/1470593106066781.

31. Vargo, Stephen L., and Robert F. Lusch. "Service-Dominant Logic: Continuing the Evolution." Journal of the Academy of Marketing Science, 2008. https://doi.org/10.1007/s11747-007-0069-6.

32. Breidbach, Christoph F, and Paul P Maglio. "Technology-Enabled Value Co-Creation: An Empirical Analysis of Actors, Resources, and Practices.” Industrial Marketing Management 56 (2016): 73-85.

https://doi.org/https://doi.org/10.1016/j.indmarman.2016.03.011.

33. Rajapakse, Chathura, and Takao Terano. "An Agent-Based Implementation of Service System Interactions Based on the ISPAR Model." In Agent-Based Approaches in Economic and Social Complex Systems VIII, 2015. https://doi.org/10.1007/978-4-43155236-9_13.

34. Troisi, Orlando, Mara Grimaldi, and Antonella Monda. "Managing Smart Service Ecosystems through Technology: How Icts Enable Value Cocreation." Tourism Analysis 24, no. 3 (2019). https://doi.org/10.3727/108354219X15511865533103.

35. West, Shaun, Paolo Gaiardelli, and Mario Rapaccini. "Exploring Technology-Driven Service Innovation in Manufacturing Firms through the Lens of Service Dominant Logic.” IFAC-PapersOnLine 51, no. 11 (2018): 1317-22. https://doi.org/10.1016/j.ifacol.2018.08.350.

36. Maglio, Paul P. "Editorial Column—Smart Service Systems.” Service Science 6, no. 1 (2014). https://doi.org/10.1287/serv.2014.0065.

37. Allmendinger, Glen, and Ralph Lombreglia. "Four Strategies for the Age of Smart Services." Harvard Business Review, 2005.

38. Vargo, Stephen L., Kaisa Koskela-Huotari, and Josina Vink. "Service Dominant Logic: Foundations and Applications." In The Routledge Handbook of Service Research Insights and Ideas, 2020.

39. Barkai J. The Outcome Economy: How the Industrial Internet of Things is Changing Every Business. CreateSpace Independent Publishing Platform; 2016. Abramovici, M. In Lapierre, L., Reinhardt, G. (eds.) CIRP Encyclopedia of Production Engineering, pp. 1-5. Springer, Heidelberg; 2014

40. Yin, R. K. Case Study Research: Design and Methods (5th Ed.). Thousand Oaks, CA: SAGE Publications, 2014.

41. Bell, E., Bryman, A., \& Harley, B. (2011). Business research methods. Third edition. Oxford University Press. Oxford, UK. 